Department of Preventive

Medicine, Kaunas

University, Kaunas,

Lithuania

Aurelijus Veryga

lecturer

Tobacco Control

Resource Centre

BMA, Edinburgh

EH2 1LL

Tanith Muller

director

Correspondence to:

T Muller

tmuller@bma.org.uk the tobacco industry operates in similar ways throughout the world, much can be achieved through sharing of information across national boundaries. All EU governments are expected to have ratified the WHO Framework Convention on Tobacco Control by the end of 2005. The world's first public health treaty commits governments to take action to reduce the disease, disability, and death caused by tobacco. The evidence based policies that it containssuch as increases in tobacco tax, advertising bans, smoke-free public places, and hard hitting picture warnings-have been proved to work. It's time for Europe's doctors to treat tobacco dependence in their patients. But it's also time to move out of the consulting room and demand that our governments take effective action too.

Competing interests: None declared.

1 Didkowska J, Manczuk M, McNeill A., Powles J, Zatonski W. Lung cancer mortality at ages 35-54 in the European Union: ecological study of evolving tobacco epidemics. $B M J$ 2005:331:189-91.

2 Gilmore A, McKee M. Tobacco and transition: an overview of industry investments, impact and influence in the former Soviet Union. Tob Control investments, impar

Boyle P, Ferlay J. Cancer incidence and mortality in Europe, 2004. Ann Oncol 2005; 16:481-8.

4 ASPECT Consortium. Tobacco or health in the European Union-past, present and future. Luxembourg: Office for Official Publications of the European Communities, 2004.

5 Doll R, Peto R, Boreham J, Sutherland S. Mortality in relation to smoking: 50 years' observation on male British doctors. BMJ 2004;328:1-10.

\title{
Comparison of amount of biomedical research originating from the European Union and the United States
}

Elpidoforos S Soteriades, Matthew E Falagas

Department of Environmental Health, Harvard School of Public

Health, Boston, MA

Elpidoforos S

Soteriades

research fellow

Alfa Institute of Biomedical Sciences (AIBS), 9 Neapoleos Street, 15123 Marousi, Athens Greece Matthew E Falagas director

Correspondence to: M E Falagas, m.falagas@aibs.gr

BMJ 2005;331:192-5

\section{Abstract}

Objective To examine and compare the research productivity of the European Union, the four "candidate" countries (those currently waiting to join the EU), and the United States in several fields of biomedical sciences.

Design A retrospective observational

study-bibliometric analysis.

Data sources Manuscripts published by authors from each country separately and from each group of countries for the period 1994 to 2004 and included in the Essential Science Indicators database of the Institute of Scientific Information.

Main outcome measures Number of published articles and number of citations, adjusted for gross domestic product and population size.

Results 1485749 articles were published by authors from the EU compared with 1356805 from the US. The research productivity of the first 15 countries to join the EU, adjusted for population, was lower $(76 \%)$ than that of the US-and even lower (66\%) when the 10 newest EU countries were included in the analysis. Conclusion The newest EU members and the EU candidate countries need further help and resources to increase their productivity, thereby improving the productivity of the EU as a whole.

The European Union and the United States are the leading powers in biomedical research and publications, although the US is ahead of the EU in most scientific disciplines. ${ }^{12}$ The EU has been gradually closing this gap, but the union's future expansion might widen the gap again in favour of the US. ${ }^{3}{ }^{4}$ We examined the biomedical research output of the EU's member countries and of four candidate countries for the EU, to compare the geographical distribution of output across Europe with the output in the US.

\section{Methods}

Our study covered the period 1994 to 2004 . We examined data for the US plus three groups of European

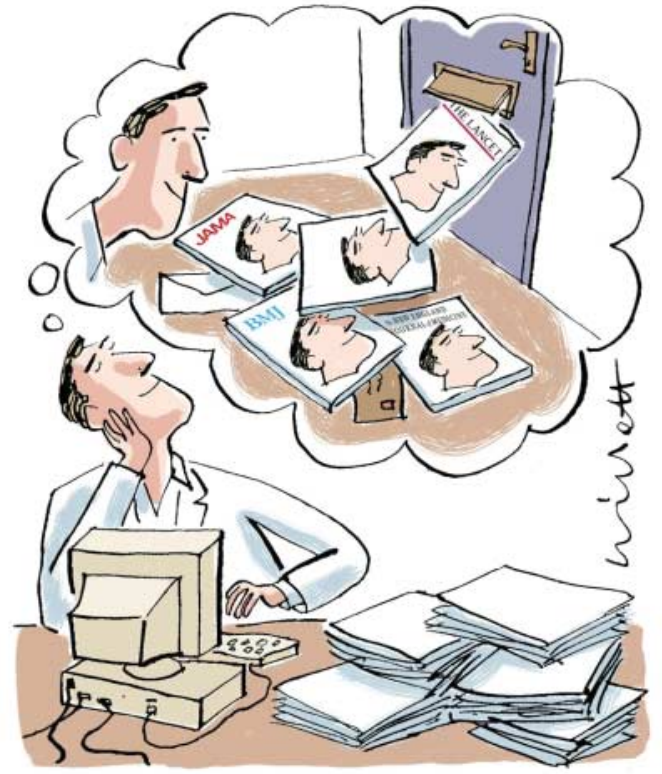

countries: (a) the first 15 states joining the EU (including three-Austria, Finland, Sweden-that did not join until January 1995); (b) the 10 countries that joined the EU in May 2004; and (c) the four "candidate" countries waiting to join (Bulgaria, Croatia, Romania, Turkey). We estimated the amount of research produced by each country separately and by each group, using the information included in the Essential Science Indicators database of the Institute for Scientific Information. A paper was attributed to any country (or countries) if an address for that country was given by one or more authors; therefore an article could be attributed to more than one country.

We focused our search on nine scientific fields: biology and biochemistry; clinical medicine; immunology; microbiology; molecular biology and genetics; multidisciplinary; neuroscience and behaviour; psychiatry and psychology; and pharmacology and toxicology. 
We used the online World Bank database to retrieve information on the average population size, the mean gross domestic product, and percentage of gross domestic product devoted to research and development. ${ }^{5}$

\section{Results}

We identified 1485749 articles published by authors from the European Union and the four candidate countries and 1356805 articles published by US authors. In the table we present raw and adjusted indicators for each country (adjusted for population size, gross domestic product, and percentage of gross domestic product devoted to research and develop- ment) and the average indicators for the different subgroups and the US. The research productivity for the group of original 15 member states of the EU, adjusted for population, was three quarters $(76 \%)$ of the productivity of the US, but when the 10 newest members were also included, EU productivity declined to $66 \%$, and when the four candidate countries were also included, EU productivity reduced further, to $55 \%$. However, after adjustment for funds devoted to research and development, the number of published articles from the $25 \mathrm{EU}$ member states plus the candidate countries is much higher than the number of published articles from the US.

Biomedical research productivity in Europe and United States, 1994-2004

\begin{tabular}{|c|c|c|c|c|c|c|c|c|c|c|c|}
\hline Countries & $\begin{array}{l}\text { Average } \\
\text { population } \\
\text { (millions) }\end{array}$ & $\begin{array}{l}\text { Average } \\
\text { GDP (\$bn) }\end{array}$ & $\begin{array}{l}\text { Average \% } \\
\text { of GDP for } \\
\text { R\&D }\end{array}$ & No of papers & No of citations & $\begin{array}{l}\text { No of } \\
\text { scientific } \\
\text { fields } \\
\text { covered }\end{array}$ & $\begin{array}{c}\text { Papers per } \\
1000 \\
\text { population }\end{array}$ & $\begin{array}{l}\text { Papers } \\
\text { per \$bn }\end{array}$ & $\begin{array}{l}\text { Papers per } \\
\text { \$bn for R\&D }\end{array}$ & $\begin{array}{c}\text { Citations } \\
\text { per } 1000 \\
\text { population }\end{array}$ & $\begin{array}{c}\text { Citations } \\
\text { per } \$ b n\end{array}$ \\
\hline \multicolumn{12}{|l|}{ EU-15 } \\
\hline Austria & 8 & 255.8 & 1.8 & 34367 & 371988 & 9 & 4.3 & 134 & 747 & 46.5 & 1454 \\
\hline Belgium & 10.2 & 300.6 & 1.9 & 46218 & 596719 & 9 & 4.5 & 154 & 809 & 58.4 & 1985 \\
\hline Denmark & 5.3 & 197.3 & 2.0 & 37297 & 497486 & 9 & 7 & 189 & 944 & 93.7 & 2522 \\
\hline Finland & 5.2 & 151.4 & 3.0 & 35498 & 477656 & 9 & 6.8 & 234 & 782 & 92.6 & 3156 \\
\hline France & 5.6 & 1687.40 & 2.2 & 197103 & 2311762 & 9 & 3.4 & 117 & 531 & 39.5 & 1370 \\
\hline Germany & $82.1^{*}$ & $2590.00^{*}$ & 2.4 & 273235 & 3201982 & 9 & 3.3 & 105 & 439 & 39 & 1236 \\
\hline Greece & 10.5 & 132.4 & 0.6 & 16840 & 108057 & 9 & 1.6 & 127 & $2132^{*}$ & 10.3 & 816 \\
\hline Ireland & 3.7 & 92.4 & 1.2 & 11453 & 121980 & 9 & 3.1 & 124 & 1031 & 32.5 & 1321 \\
\hline Italy & 57.5 & 1166.70 & 1.0 & 142179 & 1536621 & 9 & 2.5 & 122 & 1218 & 26.7 & 1317 \\
\hline Luxemburg & 0.4 & 22.5 & Not available & 474 & 4588 & 7 & 1.1 & 21 & Not available & 10.7 & 204 \\
\hline Netherlands & 15.8 & 467.2 & 2.0 & 95152 & 1250423 & 9 & 6 & 204 & 1019 & 79.3 & 2677 \\
\hline Portugal & 10.1 & 121.8 & 0.7 & 7732 & 64647 & 9 & 0.8 & 63 & 909 & 6.4 & 531 \\
\hline Spain & 40.1 & 662.4 & 0.9 & 80899 & 688465 & 9 & 2 & 122 & 1357 & 17.2 & 1039 \\
\hline Sweden & 8.9 & 274 & 4.0 & 78426 & 1042495 & 9 & $8.8^{*}$ & $286^{*}$ & 716 & $117.6^{*}$ & $3806^{*}$ \\
\hline United Kingdom & 58.7 & 1.252 .60 & 1.9 & 337 969* & $3878795^{*}$ & 9 & 5.8 & 270 & 1420 & 79.5 & 3726 \\
\hline \multicolumn{12}{|l|}{ EU-10 } \\
\hline Cyprus & 0.7 & 10 & 0.2 & 141 & 1739 & 4 & 0.2 & 14 & 705 & 2.3 & 174 \\
\hline Czech Republic & 10.3 & 54.7 & 1.2 & 10775 & 70140 & 9 & 1 & 197 & 1632 & 6.8 & 1283 \\
\hline Estonia & 1.4 & 4.9 & 0.6 & 1670 & 13269 & 9 & 1.2 & $340^{*}$ & $5566^{*}$ & 9.6 & $2703^{*}$ \\
\hline Hungary & 10.1 & 51 & 0.7 & 12289 & 100213 & 9 & 1.2 & 241 & 3414 & $9.9^{*}$ & 1966 \\
\hline Latvia & 2.4 & 5.8 & 0.4 & 342 & 3187 & 7 & 0.1 & 59 & 1710 & 1.3 & 548 \\
\hline Lithuania & 3.5 & 8.7 & 0.6 & 942 & 8060 & 8 & 0.3 & 108 & 1884 & 2.3 & 928 \\
\hline Malta & 0.4 & 3.7 & Not available & 7 & 63 & 1 & 0 & 0.2 & Not available & 0.2 & 17 \\
\hline Poland & $38.6^{*}$ & $131.6^{*}$ & 0.7 & $20572^{*}$ & $122053^{*}$ & 9 & 0.5 & 156 & 2236 & 3.2 & 928 \\
\hline Slovakia & 5.4 & 22.2 & 0.8 & 5755 & 27756 & 9 & 1.1 & 260 & 3197 & 5.2 & 1252 \\
\hline Slovenia & 2 & 21.7 & 1.5 & 3365 & 19691 & 8 & 1.7 & 155 & 1020 & $9.9^{*}$ & 907 \\
\hline \multicolumn{12}{|l|}{ EU-CCs } \\
\hline Bulgaria & 8.2 & 12.4 & 0.6 & 3531 & 14861 & 8 & 0.4 & $285^{*}$ & $5044^{\star}$ & 1.8 & $1199^{*}$ \\
\hline Croatia & 4.5 & 21.6 & 0.6 & 3794 & 18107 & 9 & $0.8^{*}$ & 175 & 2918 & $4^{*}$ & 837 \\
\hline Romania & 22.5 & 34.5 & 0.5 & 1325 & 8538 & 9 & 0.1 & 38 & 779 & 0.4 & 247 \\
\hline Turkey & $65.7^{\star}$ & $192.2^{\star}$ & 0.5 & $26399^{*}$ & $197240^{*}$ & 9 & 0.4 & 137 & 2750 & 3 & 1026 \\
\hline \multicolumn{12}{|l|}{ Totals } \\
\hline EU-15 & 375.1 & 9374.5 & 1.9 & 1394842 & 16153664 & & $\begin{array}{c}3.72 \\
(0.8-8.8) \dagger\end{array}$ & $\begin{array}{c}149 \\
(21-286) \dagger\end{array}$ & 764 & $\begin{array}{c}43.1 \\
(6.4-117.6) \dagger\end{array}$ & $\begin{array}{c}1723 \\
(204-3806) \dagger\end{array}$ \\
\hline EU-10 & 74.8 & 314.3 & 0.82 & 55858 & 366171 & & $\begin{array}{c}0.75 \\
(0.02-1.7) \dagger \\
\end{array}$ & $\begin{array}{c}178 \\
(0.2-340) \dagger \\
\end{array}$ & 2173 & $\begin{array}{c}4.9 \\
(0.2-9.9) \dagger \\
\end{array}$ & $\begin{array}{c}1165 \\
(17-2703) \dagger\end{array}$ \\
\hline EU-CCs & 101.0 & 260.7 & 0.51 & 35049 & 238746 & & $\begin{array}{c}0.35 \\
(0.1-0.8) \dagger\end{array}$ & $\begin{array}{c}134 \\
(38-285) \dagger\end{array}$ & 2635 & $\begin{array}{c}2.4 \\
(0.4-4.0) \dagger\end{array}$ & $\begin{array}{c}916 \\
(247-1199) \dagger\end{array}$ \\
\hline EU-25 & 450.0 & 9688.8 & 1.9 & 1450700 & 16519835 & & 3.2 & 150 & 784 & 36.7 & 1705 \\
\hline $\begin{array}{c}\text { EU-25 plus } \\
\text { EU-CCs }\end{array}$ & 551.0 & 9949.5 & 1.9 & 1485749 & 16758581 & & 2.7 & 149 & 797 & 30.4 & 1684 \\
\hline US & 278.4 & 8930.50 & 2.7 & 1356805 & 23801368 & 9 & 4.9 & 152 & 563 & 85.5 & 2665 \\
\hline
\end{tabular}

GDP=gross domestic product

EU-15=first 15 members of the European Union.

EU-10=next (latest) 10 countries to join the European Union (1 May 2004).

$\mathrm{EU}-\mathrm{CCS}=$ candidate countries (those waiting to join the European Union).

EU-25=EU-15 plus EU-10.

${ }^{*}$ First ranking country in each group and in each column.

†Range in parentheses. 


\section{Discussion}

The original $15 \mathrm{EU}$ states have some of the strongest publication records, and their ranking individually within that group changes depending on the indicator used. For example, raw numbers favour the United Kingdom, Germany, France, and Italy (the four most populous countries), whereas adjusted indicators favour the Scandinavian countries and the Netherlands. The research productivity of many of the original member countries, adjusted for population size or for funds devoted to research and development, far exceeds the productivity of the US, but productivity for the EU as a whole, adjusted for population, is only two thirds that for the US. Furthermore, some of the 10 newest EU states (Slovenia, Hungary, Estonia, and the Czech Republic) have higher indicators than the lowest ranking countries of the original $15 \mathrm{EU}$ states. The four candidate countries, in general, have lower indicators than the 10 newest EU states, with the exception of publications per billions of US dollars devoted to research and development, where they rank higher.

The negative geographical gradient from north to south and west to east, evident by other indicators, is also present in the biomedical research within the European Union. ${ }^{6}$ Although the US leads the biomedical research race by most indicators, the original group of $15 \mathrm{EU}$ states as a whole was not far behind. Moreover, US based journals are more heavily represented than European journals in the Institute for Scientific Information's databases, ${ }^{7}$ therefore affording the US an advantage not adjusted for in our comparison. However, the accession of the 10 newest EU states resulted in a substantial dilution of research indicators and a considerable increase in the publication gap in relation to the US, which is due to worsen with the planned accession of candidate countries, excluding the indicator adjusted for funds devoted to research and development.

Given the importance of biomedical research in economic development, we urge the EU governing bodies, along with the scientific community, to further strengthen research networks of excellence in the EU and continue to increase funding opportunities in biomedical research (as has happened with the sixth

\section{What is already known on this topic}

The European Union and the United States are the leading powers in biomedical research and publications, although the US is ahead of the EU in most scientific disciplines

The EU has been gradually closing this gap, but the union's future expansion might widen the gap again in favour of the US

\section{What this study adds}

Research productivity for the $\mathrm{EU}$ as a whole, adjusted for population, is only two thirds that for the US and may dip further in relation to the US once the four candidate countries join the union

framework programme in support of research in the $\mathrm{EU}$ and the candidate countries, as well as in some eastern European countries not in the EU). ${ }^{8}$ Furthermore, the newest EU members and the candidate countries need particular attention to increase their research productivity and improve their indicators, thus raising productivity for the $\mathrm{EU}$ as a whole.

We thank Ioannis A Bliziotis and Evi Papastamataki for their help with data collection and analysis.

Contributors: ESS and MEF designed the study, supervised data collection and analysis, and wrote the report. MEF is the guarantor.

Funding: None.

Competing interests: None declared.

Ethical approval: Not needed.

1 Vergidis PI, Karavasiou AI, Paraschakis K, Bliziotis I, Falagas ME. A bibliometric analysis of global trends of research productivity in microbiology. Eur J Clin Microbiol Infect Dis 2005;24:342-6.

2 Rosmarakis ES, Vergidis PI, Soteriades ES, Paraschakis K, Papastamataki PA, Falagas ME. Estimates of global production in cardiovascular diseases research. Int J Cardiol 2005;100:443-9.

3 Stossel TP, Stossel SC. Declining American representation in leading clinical-research journals. N Engl J Med 1990;322:739-42.

EU eliminates citation gap with America. Nature 1997;387:537.

EU eliminates citation gap with America. Nature 1997;387:537.
The World Bank. World development indicators 2002. CD Rom. 2004.

6 Manfrass K. Europe: south-north or east-west migration? Int Migr Rev Manfrass K. Europe: south-north or east-west migration? Int Migr Rev 1992;26:388-400.

Zetterstrom R. Bibliometric data: a disaster for many non-American biomedical journals. Acta Paediatr 2002;91:1020-4.

8 Auger JM, Lymberis A. Current and future R\&D activities of the EC-IST programme in eHealth. Stud Health Technol Inform 2004;108:81-7.

\title{
Commentary: Bridging the gaps in biomedical research
}

\author{
Stella Fatovic-Ferencic
}

Croatian Academy of Arts and Science Department for the History and

Philosophy of

Science, Division for

the History of

Medicine, Zagreb,

Croatia

Stella

Fatovic-Ferencic

professor

stella@hazu.hr
Soteriades and Falagas ${ }^{1}$ and Burazeri and colleagues ${ }^{2}$ explored the distribution of quality research on either side of the Atlantic and in southeastern Europe. The well known North-South and West-East divides re-emerged. The authors emphasise the negative influence that the accession of the new member states will have on the total scientific output of the European Union, as well as the greater productivity of US authors that already exists.

Science is the environment of different traditions that are unequally distributed among countries and cultures. Historically, its development is deeply rooted in social and cultural processes and often imbued with aspects of power, authority, and control. Totalitarian dictatorships provided us with a variety of examples, but democracies provided some examples as well. Reflecting on how science was transformed through the mediation of unequal power relations is necessary if we are to attempt to rethink strategies for bridging the existing gaps in biomedical research.

Political and economic experiences are a structural part of modern knowledge. We can hardly discuss knowledge or science without considering the political and economic dimensions of their emergence and use. The West-East and North-South gradients in scientific output are surely related to availability of resources, 